\title{
ORIGEN Y DIFUSIÓN DE LA LEYENDA DE PE- DRO TELONARIO Y SUS DERIVACIONES EN EL TEATRO DEL SIGLO DE ORO
}

\section{(MIRA DE AMESCUA Y FELIPE GODINEZ)}

Mira de Amescua (I574?-I644) y Felipe Godínez (I585-I639?) son autores de sendos autos sacramentales titulados, respectivamente, 1'edro Telonario ${ }^{1}$ y El Prenio de la Limosna y Rico de Alejandria ${ }^{2}$, en que se sirven de un mismo episodio para ilustrar la virtud de la caridad. Se trata, en ambos casos, de ejemplos de teatro sacramental aún según el esquema primitivo, consistente en dar forma escénica a una leyenda piadosa, con la intervención de personajes reales y alegóricos, cerrándola con la apoteosis de la Eucaristía, más o menos justificada dramáticamente. Un rico avariento se ve importunado por un pobre que va a su puerta a pedir limosna. Para apartarlo de su presencia, le arroja un pan, que el pobre recoge como si hubiera sido dado por caridad. Transcurridos dos días, el rico cae gravemente enfermo y en su delirio tiene una visión: ha muerto y se halla ante el tribunal de Dios. En una balanza se van a pesar sus actos. Las malas obras se amontonan en uno de los platillos, mientras que el otro permanece vacío, pues ninguna buena obra pueden aportar sus ángeles protectores. Al fin, se atreven a colocar en el platillo el pan arrojado al pobre, y la balanza recobra el equilibrio. El rico comprende, entonces, la fuerza de la caridad. Restablecido de su dolencia, decide cambiar de vida, dar cuanto posee a los pobres, llegándose a vender a si mismo como esclavo.

El antecedente más antiguo conocido de esta leyenda se remonta a los primeros siglos del Cristianismo y nos ha llegado en forma de epi-

1 Mira de Amiscun, Tealro, I (ed. A. Valbulena Prat), Madrid, EspasaCalpe, "Clásc. Cast.n, Ig26.

2 Iigura en Navidad y Corpus Christi Festejados. Madrid, I664. 
sodio de la vida de San Juan el Limosnero, patriarca de Alejandria, muerto en Chipre, su país natal, hacia el año 620. La primera biografía completa del citado santo se debe a su contemporáneo y amigo. I,eoncio de Neápolis (cn Chipre), y en ella figura ya el episodio de referencia ${ }^{1}$. Recogido después, según se supone, por el hagiógrafo de la Iglesia griega, Simeón Metafrasto (s. $\mathrm{x}$ ), figura ahora en la serie $\mathrm{Pa}$ trologiae Graecae (ed. J. P. Migné) ${ }^{2}$, en la conmemoración de San Juan el Limosnero (23 de enero), bajo el título de Historia S. Petri Telonarii. La versión castellana de esta historia es como sigue:

-Y añadia (San Juan el Limosnero) otro relato que un creyente fidedigno decia haber escuchado en Chipre, y poniéndolo por testimonio auténtico narraba asi: cuando yo vivia en $A$ frica, estaba al servicio de un publicano, rico en bienes pero pobre en misericordia. Como suele ser costumbre, en invierno, en las horas de sol, se reunian los pobres en busca de su calor. $Y$, como también es costumbre, hacian entonces un recuento de las casas caritativas y que comunicaban sus bienes, y otro de aquelias de las que mada recibinn, reservando para las primeras palabras de alabanza y de insulto parn lass segunclas. Iintre estas últimas se hallaba la de mi señor. Los pobres se interrogaban mutuamente sobre si alguno habla recibido limosna en alguna ocasión, y como ninguno contestara afirmativamente, uno de ellos dijo: "¿Qué me daréis si hoy, a la vuelta, os digo que he logrado obtener limosna?" Hecha la apuesta, el pobre se dirigió a la casa del publicano, llegando a la parte posterior del vestíbulo en el preciso momento que el panadero iba con su mula a entregar el pan. El publicano, que vio desde el vestibulo como el pobre intentaba con su andrajosa presencia incitarle a piedad -el pobre no osaba decir palabra para no incomodar al inclemente-, presa de furor, cogió un pan y, como quien tira uıı piedra, se lo arrojó. Cogiólo el pobre sin dilación, y, mostrándolo luego a sus compañeros, les contaba que lo habia recibido de propias manos del publicano. Apenas transcurridos dos días, el publicano cayó gravemente enfermo y vio, en su delirio, cómo se le pedia cuenta de sus acciones. Ante él tenfa una balanza; junto al platillo izquierdo se hallaban unos negros ocupados en ir colocando en la balanza sus muchas malas acciones. A la derecha, unos hombres vestidos de blanco, y de apariencia terrible, mostraban semblantes tristes y compungidos, pues nada podian colocar en su platillo para contrapesar. "Nada tenemos - decian- si no ese pan que anteayer dio a un pobre, si bien no por propia voluntad". Lo pusieron en la balanza y ésta quedó equilibrada. Acto seguido, los que vestian cándidas ropas dijeron: "Vuelve a tu casa y añade tus obras a este pan. Si no lo haces, los negros se apoderarán de ti". Al volver en sí, el publicano pudo darse cuenta de que el sueño que habia tenido era verdad, pues vela, como

1 Esta biografia fue editada a finales del siglo pasado, en original griego, por HEINRICI GeIzER: Lrontros VON NEAPOIIS. Leben des Heiligen Johannes' des Barmherzigen, Erzbischofs von Alcxandrien. Freiburg i.B. und Leipzig; 1893. Algo anteriores a la obra de Leoncio son los fragnentos biográficos debidos a Sofronio de Jerusalem y a Juan Mosco, que Lreoncio completa en su obra.

= Towus CXIV, I903, pp. 927-934. 
entre tanto, los etiopes ${ }^{1}$ iban colocando en la balanza todas las obras que habia lieclıo desde su juventud y que él tenia olvidadas ya. "iPadre míol -exclamó estupefacto el publicano- ¡Tanta es la fuerza de la limosna! Si un solo pan y aun arrojado tanto puede, ¿de cuáutos males se podrá librar quien halla gozo en repartir sus bicncs cutre los pobres?" $\Lambda$ partir de entonces, el publicano dio limosna con tal abundancia; que llenó, como suele decirse, el vientre de los pobres; y ni siquiera tuvo compasión de su propio cuerpo, pues, renunciando a la libertad, alimentó también con él a los necesitados, como diremos más abajo. Sucedió que, yendo un día al telonio, encontró a un marinero desnudo que se habia salvado de un naufragio. Al verlo, el publicano se deshizo de su vestido, que era delicado y suntuoso, y se lo dio, encareciéndole que lo conservara y lo vistiera siempre. Ill marinero se fue, y ya porque el vestido le pareciera demasiado rico, ya porque necesitara otras cosas, lo expuso en la plaza y lo vendió. Acertó a pasar por alli el publicano, quien, viendo el vestido colgado, sintió gran dolor y tristeza, pues pensó que no labia sido aceptada su caridad. En tales reflexiones le sobrevino el sueño y tuvo una visión: se le apareció un hombre insigne, más resplandeciente que el sol, que tenia una cruz sobre la cabeza y que llevaba puesto el vestido que liabia dado al marinero. La aparición, acercándosele, le dijo: "¿Por qué estás triste y afligido, anigo Pedro?"' (que éste era el nombre del publicano). Y él, como si conocicra con quien estalua hablando, contestó: "Scñor, porque vemos que las cosas que tí nos das en alundancia y que nosotros connunicamos, no son usadas rectamente sino malversadas por afán de lucro". Apenas pronunciadas estas palabras, la aparición, mostrándole el vestido que llevaba puesto, dijo: "¿Io reconoces?" Al afirmar el publicano, añadió: "Desde que tú me los has dado, lo llevo puesto". Al despertar de su sueño, el publicano exclamó: "¡Alabado sea Diosl Si acabo de ver que Cristo es uno de los pobres, no cesaré liasta convertirne en el más pobre entre ellos". Acto seguido, llamó a su mayordomo, que habia sido comprado por él, y le dijo: "Voy a confiarte un secreto. Advierte que, si no sabes guardarlo, te alejaré de mi presencia y te venderé en tierra extranjera". Diciendo esto, le eutregó diez libras de oro destinadas a la transacción que se disponian a realizar. $Y$ el publicano añadió: "Yo soy parte de este negocio (tal es el secreto). Llévane a la Ciudad Santa y véndenle como esclavo a un cristiano; el precio que recibieres, dáselo a los pobres". De nada sirvieron las protestas del mayordomo. Este último. una vez llegados los dos a Jerusalem, dio con cierto aunigo, de noubre Zoilo y de profesión platero, que habia caido en la pobreza. Il mayordomo se dirigió a él y le dijo: "Tengo un esclavo muy bueno. Si siguiendo mi consejo, lo compras, no tardarás en verte restituido a tu antiguo estado y oficio, pues el tal esclavo no sólo es honrado, sino que, además, conoce muy bien el oficio de orfebre". (Pues Pedro se había dedicado también a este empleo.) Zoilo dijo que no podia comprarlo por la pobreza en que se liallaba, pero, al fin, pidió oro prestado y por treinta monedas adquirio al diligente Pedro. Recibido el dinero, el mayordomo se fue a Constantinopla. Digno era de verse como el que había aceptado libremente la esclavitud por el amor de Cristo, servia con diligencia a su señor en todas las necesidades de la casa y observaba el ayuno y las vigilias. Cuanto hacia tenía por fin acrecentar los bienes de su señor para que, como a Job ${ }^{2}$, la opulencia le resarciera de la pobreza. El que lo habia comprado, viendo su virtud, quiso librarlo. Pero Pedro

1 I a palabra etfope significa 'de rostro tostado'.

2 Job XIIII, I2. 
prefirib la esclavitud por Cristo que descansar en la libertad. ¿A quién podré contar las penalidades que le infligió cl espiritu del mal? Los otros criados, teniéndolo por loco, se relan de él; también le daban bofetadas y le causaban pesadumbre. Siempre que se acostaba entristecido por los malos tratos de sus compañeros, se le mostraba ch sucĩos aquel que se le habla apareciclo en $A$ frica, llevando su vestido y las treinta monclas, y le decía: "No estés triste, hermano Pedro; mira que he accptado el precio cono antes acepté cl vestido". Pasado algún tiempo, unos que cran de la misma región que Pedro, también plateros de oficio, fueron a Tierra Santa para venerar los lugares. El dueño de Pedro los recibió y alojó con satisfacción, pues eran del mismo oficio. Pedro los reconoció mientras les servia a la mesa, haciendo lo posible para esconderse. Sus paisanos, después de muchas dudas, también lo reconocieron, y dijeron a su luuésped: "¿Qué está lraciendó este hombre a tu servicio, siendo uno de los senadores y no excediéndole nadie en magnificencia? Fste que nos está sirviendo es Pedro el publicano, cuya desaparición ha llenado de tristeza al emperador y al senado". Pedro, al oír esto, dejó cacr la ban-. deja que llevaba, salió hacia el vestibulo, donde un adolescente sordomudo de nacimiento cumplia por señas el oficio de portero. Pedro le dijo: "A ti te lo digo: cn nombre de Cristo, nuestro Dios, escuclia y abre la puerta". In adolescente contcsti: "Como ordenas". Iin suguida alurio y Palro huyó corricndo. Ial portero

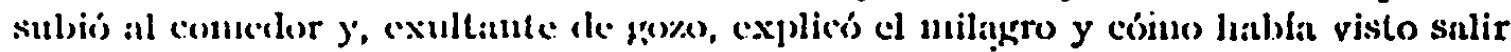
de la bocia del gram l'idro man llama due le tocó las orejas y le circundó, haciendo que oyera y liablata. Todos quedaron achiniralos y salicron cu busca de Pedro, pero fue inutil, pues no lo hallaron. Lintonces sintieron necesidad de hacer penitencia y se arrepintieron de su falti de consideración lacia aquel hombre de Dios, al que habian afrentado, maltratado y hecho objeto de continuas irrisiones».

Nada se dice de la vida ulterior ni de la muerte de Pedro Telonario. De este modo pasó esta piadosa leyenda a la tradición de la Iglesia latina, siendo, sin duda, ésta una de las causas de que la narración no rebasara nunca su carácter episódico. No sucede así en la tradición de las Iglesias orientales; el Sinaxario copto conmemora la fiesta de San Pedro Telonario y añade que éste, al ser reconocido por sus paisanos, huyó al desierto en busca del anacoreta Macario y terminó sus días dedicado a las prácticas piadosas. También el Menologio griego celebra su fiesta y dice que Pedro huyó a Jerusalem (que es precisamente donde se hallaba) y que su cuerpo se venera en Bizoncio. Además no deja a Pedro en la categoría de simple 'telonario', sino que dice de él que podría haber llegado a exarca de Africa ${ }^{1}$. Poner al "santo" en posición social ventajosa para resaltar así el mérito de su renuncia, es un recurso muy común en las leyendas del género. Se observa ya en la versión que hemos transcrito, en que después de decirse repetidamente que el oficio de Pedro era el de publicano se le reviste al final de la dignidad de senador $y$ se subraya que el emperador lamenta su desaparición.

1 Cf. Hreinkicil Gilzier, op. cil., p. I38 s. 
Una de las obras más divulgadas en la Eidad Media, la Legenda Aurea (hacia 1270), de Jacobo de Voragine, contribuiría sin duda a difundir por toda Europa el episodio de Pedro Telonario. El relato que del mismo se hace en ella es un breve resumen del de Metafrasto y se ajusta a él en térninos generales ${ }^{1}$. Sin embargo, sin insistir en el lugar de la acción, se da como domicilio de Pedro, no la provincia africana de Alejandría, sino Constantinopla, la capital del imperio. Además, en la escena del juicio se refleja también el cambio político operado en los siglos transcurridos; los malos espiritus que quieren arrebatar al alma del avariento ya no son negros o etíopes, sino moros.

Desglosada de la vida de San Juan el Limosnero se conservan además numerosas versiones de esta leyenda, en forma de ejemplo moral, en manuscritos de los siglos XIII, XIV y XV, de muy diversa procedencia, en latín y en lengua vulgar. La mayor parte de tales manuscritos se limita a relatar la prodigiosa visión de Pedro y su conversión, sin entrar en los detalles de sus prácticas caritativas. In algunos se conserva el nombre de l'edro y se pone de relieve su profesion de publicano ${ }^{2}$. lin otros, se insiste en convertirle en "richo e sentile e molto caro delecto de lo inperadore" ${ }^{3}$, o aparece como alto dignatario de la Corte de Constantinopla, que, más en consonancia con su rango, no arroja un pan sino una moneda a la cara del importuno que pide limosna a la puerta de la iglesia ${ }^{4}$. Es constante en tales documentos el detalle de situar la acción en Constantinopla. Así se hace también cn una muestra castellana de csta parábola: la que bajo el título de "La elimosna contra voluntad dada, haun ante Dios es aprovadan figura en la obra de Clemente Sánchez de Vercial (+ 1434), Libro de los Exenplos por A. B. C., recopilación de enseñanzas morales destinada a predicadores ${ }^{9}$. Directa

1 Jacoibr a Vorngins, Legenda Aurea, Iulgo Historia Lombardica Dicta, IEd. TIl. Girarssie, Vratislaviae, 1890, p. I 27 s.

2 MS Harley 273; hacia 1300 , texto en francés, procedencia inglesa (cf. Catalogue of Romances in the Jepartment of Manuscripts in the British Museum. Vol. III, by J. A. IHIRBriRT, London, I910, p. 28I, 11.0 3r). IIS Sloaize 2478; principios s. XIV, latin (cf. Catalogue of Romances..., Vol. III, p. 515, 11.068-71). MIS Arundel 506; primera mitad s. XIv, latin, procedente del MLonasterio de $S$. Miguel de Maguncia (cf. Catalogue of Romances..., Vol. III, p. 544, $11 .{ }^{\circ} 46$ ).

3 J. Ulricri, Recueil d'Exemples en ancien Italien, Exemplo de uno homo richo che niente volea dare per dio, Romania, ISS 4 , XIII, p. 32.

- JOSEII IELAPIER, Erzählungen des Mittelalters in deutscher Ubersetzung und lateinischem Urtext. Breslau, I9r4, p. 334 s.: De Petro Thelonario; de elemosina. Reproduce un MS anterior a $\mathrm{I}_{4} \$ 5$ procedente del Convento de Doninicos de Breslau.

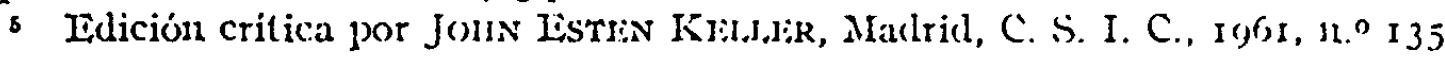
$\left(\sigma_{4}\right)$, p. II 7 s. Iit misno "excmplon figura bajo el número $\sigma_{4}$ en la clición de $P^{\prime}$. IE Gayangos en 13. A. Ii., Vol. LI, p. $4 \sigma_{3}$. 
o indirectamente en relación con la leyenda de Pedro.Telonario, hay que situar también las múltiples versiones que circulaban en la Edad Media de la visión en sueño premonitorio del juicio ultraterreno del alma, simbolizado por una balanza. Unas veces se trata de un rico avariento $y$ es San Migucl quien coloca el pan en el platillo '; otras, un mal uclercu, devoto de la Virgen, que ve cn sueños cómo los diablos quieren apoderarse de su alma presentando una larga lista de sus pecados. Pero María interviene, y con un pequeño billete logra que la balanza recobre el equilibrio. El "clerc» despierta bañado en lágrimas, teniendo en la mano el billete de Nuestra Señora ${ }^{2}$. Algo parecido se lee en el ejemplo $D u$ riche home qui jeta le pain a la teste du pauvre, en que también es la intervención de María la que produce el milagro ${ }^{3}$. En otras versiones, menos afines, es un monje disoluto quien tiene la consabida visión; en ella la Virgen le salva pidiendo a Cristo que ponga una gota de su sangre en la balanza 4; en otras es un clavo de la $\mathrm{cruz}^{5}$, un billete con las letras Ave Maria ${ }^{6}$, una vela of recida a la Virgen ${ }^{7}$, o la propia mano de Nuestra Señora lo que equilibra la balanza ${ }^{8}$. Como vemos, se va adaptando la antigua paríbola de cxaltación de la caridad al fomento de la devoción mariana. Una excepción, casi precursora de la Reforma, la tenemos en el ejemplo del pecador moribundo que, viendo sus muchas malas obras junto a las pocas buenas, exclama: "Añadid mi fe en Cristo crucificado» 9.

La leyenda de Pedro Telonario no tuvo sólo divulgación dentro del ámbito estrictamente catequístico, sino que pasó también al teatro. Una muestra es la obra dramática francesa Miracle de Pierre le Changuer. Se trata de una composición escénica de finales del siglo xIv, dentro

I IS Additional 27336; principios s. Xv, procedencia italiana, latin (cf. Catalogue of Romances..., Vol. III, p. 653, n. $\left.{ }^{\circ} 75\right)$.

2 MIORAIvSKI. Mélanges de litterature piense. Romania, I935, LXI, p. I9I.

3 J. Morawski, Melanges de litterature pieuse II, Les miracles en quatrains alexandrins monorimes: Jean de Saint Quentin. Romania, I939, IXV, pp. 327-358.

- IIS Additional 19,909; A. D. I473. Prompluarium de Miraculis de B. V. M.: latiu (cf. Catalogue of Romances..., Vol. II, by HARRY I.. D. WARD, London, I893. p. $685,11.050)$.

s MIS Additional 9066; segunda mitad s. xv; latin (cf. Calalogue of Romances..., Vol. III, p. 257, 12.0 62).

- MUSSAFL, Studien zu den mittelalterlichen Marienlegenden, III, p. 49, 12.0 50. Sitzungsberichte der Kais. Akademie der Wissenschaften, Wien, I889.

- MIUSSAFIA, ibidem, III, p. 49, n.0 49.

8 MIUSSAFIA, ibidem, II, Wien, I 888, p. 63, n. ${ }^{\circ}$ 4. Este mismo episodio figura también en el Liber Mariae, de GII, DE ZAMORA, el amigo de Alfonso X y preceptor de su hijo Sanclio (cf. MUSSAria, ibidem, III, Wien, r889, pp. 26 y 3I).

- MIS Egerton Irr7; finales siglo $\mathrm{xur}$; latín (cf. Catalogue of Romances.... Vol. III, p. 47r, 11. ${ }^{\circ}$ ). 
de la serie llamada. Miracles de Nostre Dame par Personnages, que constituían el repertorio dramático de una cofradía parisina ${ }^{1}$. Es, por lo tanto, también obra de exaltación. mariana. La acción de la misma se supone al principio en Francia y se ajusta al relato originario, añadiendo, como es natural, detalles individuales y elementos cómicos para animar las escenas. Se reproduce el episodio del marinero náufrago a quien Pedro entrega su rica vestidura, y el de la venta del propio Pedro en Jerusalem. En este punto se modifican algunos detalles: el comprador de Pedro, que también se llana "Zoille», es un rico mercader de telas de seda y oro, musulmán de religión; el precio que paga por el esclavo no es el simbólico de treinta monedas, sino de cien; Pedro, al ser reconocido por sus paisanos, no huye, sino que, por su intervención milagrosa, devuelve el don de la palabra a una hija del dueño. La pieza se cierra con la conversión del musulmán y su familia, quienes, en presencia de Pedro, reciben el bautismo de manos del patriarca de Jerusalem ${ }^{2}$.

La utilización de la leyenda de Pedro Telonario por Mira de Amescua y I'elipe Godíne\% cn sus respectivos autos l'edro Telonario y El l'remio de la Limosna y Rico de Alejandría es un testimonio más de la vigencia eil la España del siglo xvir de las tradiciones piadosas medievales. Lis de suponer que ambos dramaturgos conocerían el relato del prodigio tal como figura en el Flos Sanctorum, del P. Ribadeneyra ${ }^{3}$, tan en boga en la época y tan socorrido como fuente de inspiración de obras teatrales religiosas. Pero no es aventurado suponer, si bien carecemos de datos que lo confirmen, que las de Mira de Amescua y de Godínez no habrian sido las únicas versiones dramáticas del tema o, en todo caso, que éste habría sido ya anteriormente en España objeto de elaboración literaria. Ciertos elementos que ambos autores introducen en sus respectivos autos sugieren esta idea e incluso la de cierta influencia fran-

1 Gustav Grober, Geschichte der Mittelfranzösischen Literatur, I, Berlin und I,eipzig, I933, p. I79 s.; I. PETIT DE JULLIVILLE, Histoire du Théatre en France. Les Mysteres, Tome Premier, Paris, I880, pp. 320-322; RunoLF GLUTz, Miracles de Nostre Dame par Personnages. Kritische. Bibliographische und Neue Studien zu Text, Entstehungszeit und Herkunft, Beriin, I954.

2 Miracles de Nostre Dame par Personnages, Publiés d'après le Manuscrit de la Bibliothèque Nationale par G. PARIS \& U. ROBERT, Tome VI, Paris, I88r. La obra sobre Pedro Telonario consta de 2.1 I9 versos y en ella intervienen reinticuatro personajes.

3 Flos Sanctorum, o Libro de las Vidas de los Santos, escrito por el P. Pedro de Ribadeneyra, Barcelona, 1688, Primera Parte, p. 245 s. La edición del Flos Sanctorum de ALONSO Dr: VIILEGAS que he consultado (Barcelona, I775, pp. 7 ro712), no registra el episodio de Pedro Telonario. 
cesa. Es interesante observar que tanto Mira de Amescua como Godínez dan a Pedro el sobrenombre de "rico de Alejandría", con lo que parecen seguir una tradición que no se aparta, a diferencia de la mayoría de ejemplos aducidos, de la fuente original. Las dos piezas presentan múltiples afinidades que revelan claramente el conocimiento que un dramaturgo tuvo de la obra del otro. Incluso se interpolan los mismos elementos populares (romance marinero, baile de gitanas), en idénticas situaciones escénicas. No obstante, careciendo de datos fehacientes, no es quizás oportuno formular en este lugar hipótesis sobre el giado de urefundición. Cotarelo y Mori afirma que el auto de Godínez es posterior ${ }^{1}$. En todo caso - y no es de extrañar- el Pedro Telonario, de Mira de Amescua es mucho mejor, tanto por su calidad poética como por su unción religiosa. Se inicia según el modo acostumbrado: diálogo entre la Caridad y la Avaricia, que se disputan el dominio en el alma de Pedro Telonario. Los pobres que van a importunar a éste son peregrinos que, si bien caminan por tierras de Alejandria, entonan cantos compostelanos de clara influcncia francesa:

\footnotetext{
Tola la Francia confia que la nosira pena aplaques; per Deo e per Sancla Maria c per el señor San Jaques 2 .
}

Pedro les arroja el pan, tiene la consabida visión y despierta dispucsto a enmendar su vida. La escena primitiva del encuentro entre Pedro y el náufrago desnudo se transforma en Mira de Amescua en diálogo entre un soldado-peregrino, de nombre "Henrico", y un tal "Charlos" ${ }^{3}$, dueño de una nave que enarbola los "lirios de Francia". "Henrico" le cuenta que se ha enriquecido con las dádivas de un tal Pedro Telonario y que ahora busca pasaje para pasar a Europa. Ambos personajes insisten en su condición de franceses. Ia venta de Pedro como esclavo no tiene lugar en Jerusalem, sino en la misma Alejandría, siendo el comprador el citado "Charlos", quien paga por Pedro 29 reales, pues éste no acepta ser vendido por más precio que su Redentor. La escena de la aparición de Cristo en figura de peregrino es una reminiscencia de las visiones de que habla la leyenda primitiva. Sigue un episodio que bien puede ser del propio Mira de Amescua, pues muestra

1 Cotarelo y Mori, Comedias de Tirso de Molina, N. B. A. E., 1907, Vol. II, p. $\sin s$.

2 ed. cil., v. v. 427-30.

- Con tales ortografias figuran estos nombres en el manuscrito conservado (cf. J. Ar.LNDA, Catúlogo de los aulus sacramentales, historiales y alegóricos, BRAE. I920, VII, p. 510). 
uno de los rasgos más peculiares de este dramaturgo, el gusto por el extremismo: Pedro, arrebatado por el espíritu de caridad, no resiste el deseo de hacer limosna con un dinero que no le pertenece. El auto se cierra con el ingreso de Pedro en el Jardín de la Caridad, donde muere

\author{
de un dolor \\ repentino si violento \\ de ver que ha sido avaricnto \\ con tu pródigo señor ${ }^{1}$.
}

El Premio de la Limosna y Rico de Alejandría tiene la misma distribución escénica. Abunda más en elementos cúnicos; por ejemplo, las expresiones y estratagemas de los pobres peregrinos para arrancar una limosna a Pedro. A diferencia del auto de Mira de Amescua y de la leyenda original, son los mismos pobres que reciben el pan arrojado los que, después de la visión, reciben las ropas de Pedro. Aparece, como cn Pedro Telonario, un capitán de navio al que se insiste también en hacer francés de nación, y que es el que luego compra a Pedro. Las escenas del trato, de la aparición de Cristo y de la muerte del protagonista presentan en ambos autos la misma forma, si bien su tono es muy distinto. La figura de Pedro 'Telonario reviste en Mira y en Godínez rasgos propios de un personaje muy común en el teatro religioso del Siglo de Oro: el rico epulón de la parábola evangélica ${ }^{2}$. En ambos autos se alude repetidas veces al citado pasaje bíblico, y Godínez llega incluso a presentar a su Pedro 'Telonario sentado a la mesa entregado al vicio de la gula. Esta circunstancia y el desconocimiento del origen distinto de ambas tradiciones explica que, en algunas apreciaciones criticas, se hable del rico avariento y de Pedro Telonario como de un mismo personaje ${ }^{3}$.

Existe noticia de un auto anónimo titulado El trinnfo de la Limosna, representado en I62I, que muy probablemente se basaría también en la historia de Pedro Telonario 4 .

JOSÉ M. BELLA

1 Ed. cit., v. v. 987-90.

3 S. Lucas I6, I9-3I. El propio Mrira de Amescua hace una excelente versión dramática de la misma en V'ida y Muerte de San Lázaro: Tirso de MIolina en Tanto es lo de más como lo de menos; Rojas Zorrilla en el auto sacramental El rico avariento. Asimismo existe noticia (en El Peregrino en su Patria) de una comedia de Lope titulada El Rico avariento, hoy desconocida.

3 Cotarelo x Mori, op. y l. cit.; Varbuena Prat, Mira de Amescua, Taetro. I, ed. cil., p. 289.

- J. ALENDA, Catálogo..., BRAE, 1922, IX, p. 678. 